\section{Dra. Ana Slimovich}

Consejo Nacional de Investigaciones Científicas y Técnicas (CONICET) Universidad de Buenos Aires-Instituto de Investigaciones Gino Germani @ aslimovich@gmail.com
- Recibido / Received

10 de octubre de 2020

- Aceptado / Acepted 1 de noviembre de 2020

- Páginas / Pages De la 85 a la 102

- ISSN: 1885-365X

\title{
Pandemia global y política mediatizada. La comunicación presidencial argentina y sus repercusiones en Twitter en el primer semestre 2020
}

\section{Global pandemic and mediatized politics. Argentina's presidential communication and its impact on Twitter in the first half of 2020}

\section{RESUMEN:}

El objetivo de este artículo es indagar en las discursividades del presidente argentino en Twitter en relación con su propia conferencia de prensa por la pandemia por Covid-19 - producida en mayo de 2020-, así como en las discursividades de los internautas durante la conferencia. También se tendrán en cuenta las que se produjeron con posterioridad al anuncio presidencial de extensión de la cuarentena, en reacción con el programa Intratables cuyos temas hicieron referencia a la conferencia. Se tiene en cuenta para el análisis el momento particular histórico de la mediatización de la política, así como el contexto de pandemia mediatizada en la cual proliferan en las redes sociales informaciones inexactas, cifras $\sin$ fuentes, noticias falsas, trolls, bots, etc. Se utilizaron herramientas de la socio-semiótica para realizar el análisis comparativo. Se concluyó en la existencia de operaciones de interfaz en la red social presidencial que conjugan una «enunciación coral», así como se determinó en la existencia de dos colectivos político-mediáticos en Twitter: uno adherente al presidente que se constituye como de «internautas militantes de la cuarentena» en la Argentina, y construye «micro-argumentaciones lógicas»; y otro opositor de la cuarentena que no se ancla a ninguna fuerza política pero emerge como opositor al presidente y postula «micro-argumentaciones pasionales».

\section{PALABRAS CLAVE:}

Mediatización de la política; Conferencia de prensa; Twitter; Internautas; Colectivos; Presidente.

\section{ABSTRACT:}

The aim of this article is to explore the Argentine president's Twitter feeds in relation to his own press conference on the COVID-19 pandemic - produced in May 2020 - as well as the discourses of internet users during the conference. Those that took place after the presidential announcement of the extension of the quarantine will also be taken into account, in reaction to the Intractable programme whose themes referred to the conference. The analysis takes into account the 
particular historical moment of the mediatization of politics, as well as the particular moment of the mediatized pandemic in which inaccurate information, figures without sources, fake news, trolls, bots, etc. proliferate on social networks. SocioSemiotic tools were used to carry out the comparative analysis. It was concluded that there are interface operations in the presidential social network that combine a "choral enunciation», and it was also determined that there are two politicalmedia collectives on Twitter: one that supports the president and is constituted as «militant Internet users of the quarantine» in Argentina, and constructs «logical micro-argumentations»; and another that opposes the quarantine but does not support any political force but emerges as an opponent of the president and postulates «passionate micro-argumentations».

Mediatization of politics; Press conference; Twitter; Internet users; Collectives; President.

\section{Introducción}

Con la pandemia global por Covid-19 han cambiado las prácticas sociales, políticas, económicas y se ha producido un paso a la digitalización de muchas de ellas. A medida que se instalaba el confinamiento para luchar contra la propagación del Covid-19 en distintos países de todo el mundo, proliferaban los discursos sobre el tema en distintos medios, plataformas y formatos. Tanto profesionales de la salud como personas públicas y famosos/as, así como personas desconocidas, trolls, bots, abordan el tema, dan su opinión sobre la instalación de la cuarentena, brindan consejos en la lucha contra el virus y proponen soluciones o medidas preventivas -incluso algunas diferentes a las oficiales-. De este modo, proliferaron en distintos lugares del planeta noticias falsas en relación con el coronavirus, que se mixturan con la información oficial.

Por otro lado, las horas de confinamiento en la Argentina han provocado que el consumo televisivo se haya incrementado. En un contexto de incertidumbre como el que se está transitando, con las decisiones estatales regulando las prácticas sociales de un modo mucho más marcado que antes de la pandemia, las conferencias de prensa presidenciales han cobrado centralidad en la escena mediática.

El objetivo de este artículo es analizar las repercusiones en las redes sociales de una conferencia de prensa presidencial argentina que anunciaba la prolongación de la cuarentena en el país. Nos centraremos en la conferencia del 8 de mayo de 2020 y en sus repercusiones en Twitter. La elección de este tema se fundamenta en dos razones: por un lado, la importancia que posee el anuncio presidencial en el ecosistema mediático y el alto grado de repercusión en Twitter que genera el anuncio. Por otro lado, porque analizar las repercusiones en Twitter permite comprender la mediatización contemporánea de la política argentina en el contexto de la pandemia y de desinformación política y proliferación de mensajes y de informaciones falsas e inexactas.

\section{Estado de la cuestión}

\subsection{Mediatización de la política duRante la pandemia POR COVID-19}

El interés de análisis y construcción del objeto de estudio parte del interés en reflexionar en torno a la mediatización de la pandemia a partir de la conferencia de prensa y sus repercusiones 
en Twitter. En ese sentido resulta relevante detenernos en algunas consideraciones en torno a dos aspectos: el proceso histórico de la mediatización de la política y la conferencia de prensa en tanto acontecimiento organizado bajo lógicas políticas y mediáticas.

La mediatización - tanto desde la teoría veroniana como desde la que proviene de los países nórdicos - es conceptualizada como un proceso que posee distintas etapas con un salto y una aceleración en el último cuarto del siglo xx (Couldry, 2014; Hjarvard, 2008; 2014; Mazzoleni y Schulz, 1999; Strömbäck, 2008; Verón, 1986; 1987a; 1987b; 1998[1995]; 2001 [1984]; 2013). Esta transformación también produce cambios en la relación entre las lógicas políticas y las lógicas mediáticas'.

Desde la perspectiva de Verón (2001 [1984]), la era de los medios masivos puede dividirse en dos momentos. En una primera instancia, cuando surgen los medios tradicionales, su función se concentra en «influir» en las prácticas políticas. En efecto, en esta sociedad, que denomina «mediática», la televisión, la prensa gráfica, el cine, la radio, generan una estrategia de representación. Por el contrario, a partir de la década del 80 se genera un cambio en el proceso de mediatización de la política y surge un tipo de sociedad que Verón llama «mediatizada». En ella los medios se posicionan enunciativamente como los que «construyen la realidad». Las lógicas políticas se organizan en función de las lógicas de los medios tradicionales. La política ya no accede a los medios para buscar ser representada ante los ciudadanos (no se trata de que existan vínculos entre los dos mundos), sino que se piensa a sí misma a partir de las lógicas de los medios masivos. De este modo, en la democracia audiovisual avanzada

(...) una campaña electoral no es un proceso ajeno, en tanto tal, a los medios (forma parte, digamos, del campo de lo político) y que los medios se limitarían a reflejar, a re-producir, mejor o peor: una campaña electoral está cada vez más pensada, organizada, dosificada, en función de la televisión (Verón, 2001 [1984]: 15).

Una de las cuestiones que se pone en juego con la mediatización de la política es la gestión de los colectivos políticos (Verón, 1987b), que entran en contacto tanto con los líderes políticos como con los periodistas. Es decir, ambos los gestionan y, por consiguiente, el discurso periodístico y el político son mediadores de lo colectivo. En efecto, Verón postula que los colectivos políticos y los mediáticos se mixturan en el momento de la sociedad mediatizada.

En el momento actual, seguimos a Carlón (2015) quien considera que vivimos en una "sociedad hipermediatizada", atravesada por relaciones entre el sistema de los medios masivos - en crisis - y el de las redes sociales. Desde su perspectiva, se considera que surgen colectivos desde las redes sociales, que luego ascienden a los medios masivos y que pueden ocupar el espacio público, como los internautas en Twitter anclados a un hashtag.

Aproximarnos a la mediatización de la política, proceso histórico de imbricación del campo de lo político en el de los medios de comunicación (Verón, 1984), es sustancial para comprender el momento actual en el cual los discursos políticos están también en las redes

\footnotetext{
1/ El proceso histórico de mediatización de lo político, y el tema específico de la relación entre lo político y lo mediático, en la teoría veroniana y en las conceptualizaciones de los países nórdicos, excede el objetivo de este artículo. Una aproximación, entre otras, puede leerse en «la mediatización de lo político» (Slimovich, 2016). También se ha trabajado de modo específico la relación entre las lógicas políticas y mediáticas en el caso de la fuerza política argentina de Cambiemos en «El camino de Cambiemos en las redes sociales: entre las lógicas políticas y las mediáticas» (Slimovich, 2020).
} 
sociales. Las democracias actuales se caracterizan por instalar nuevos modos del discurso político y procesos de expansión de los actores políticos, entre los que surgen distintos tipos de internautas, que se diferencian según el tipo de relación con la red social y con el campo de lo político, así como también existen los que apuntan explícitamente a manipular la conversación política, como los trolls y bots.

En cuanto a las conferencias de prensa cabe mencionar que desde la instauración de la cuarentena en el país - el 19 de marzo - hasta junio, el presidente Alberto Fernández realizó media docena de conferencias de prensa, cadena nacional o anuncios. Consideraremos las conferencias de prensa presidenciales como «acontecimientos político-mediáticos» (Slimovich, 2011; 2016), siguiendo a Dayan y Katz (1992), quienes se refieren al «acontecimiento mediático" como un género televisivo que convoca audiencias masivas, en tiempo real con el desarrollo del evento (en directo y fuera del espacio del estudio). En otro lugar (Slimovich, 2016), hemos aunado la categoría de los autores: «acontecimiento mediático» con la transmisión televisiva de acontecimientos políticos, la conferencia de prensa de un presidente o los actos de apertura y cierre de campaña (que luego son retomados por los noticieros, programas políticos de opinión y programas de entretenimiento) y la hemos denominado «acontecimiento político-mediático»:

Se trata de un tipo de transmisión televisiva que contiene lógicas de lo político (...) también hay operando lógicas que provienen del discurso informativo televisivo, como el tipo de plano, cuál es el fragmento parcial que se replica del discurso del candidato frente al escenario, cómo lo resume la instancia en off, cómo lo relata y argumenta el especialista político, cómo se lo transmite, bajo qué dispositivo, etc. (Slimovich, 2016: 90).

En este caso, son «acontecimientos político-mediáticos» que tienen la particularidad de generar gran cantidad de información y repercusión, tanto en redes sociales como en los medios tradicionales, así como de expectación por parte de la ciudadanía. En cada uno de estos anuncios se informó sobre las nuevas medidas y el devenir de la cuarentena, diferenciando las situaciones particulares de las provincias del país.

Cabe destacar que la utilización de emisiones en directo fue un género muy utilizado por la ex presidenta Cristina Fernández de Kirchner. Lo hizo bajo la modalidad de cadena nacional -con sus múltiples interlocutores mediatizados asociados (Fernández y Cingolani, 2019) - y a la par que desplegaba en las redes un «ethos íntimo» (Gindin, 2019). Por el contrario, fue escasamente utilizada por el ex presidente Mauricio Macri, quien concentró la difusión de su comunicación política en las redes sociales de Facebook, Twitter e Instagram (Slimovich, 2017; 2019; Annunziata, Ariza y March, 2018). En el caso de las conferencias de Fernández, no se trata solamente de una cuestión de cantidad de emisiones televisivas en directo en las cuales el presidente comunica sobre la pandemia; sino y sobre todo -en un reacomodamiento de los temas y agendas de los medios en función de ese acontecimiento político-mediático - que convoca audiencias masivas, tanto por el propio aparato como a través de su transmisión en vivo por las redes sociales, y en el cual el directo televisivo con sus implicancias e imprevisibilidad, a nivel de dispositivo (Carlón, 2004) cobra relevancia.

Por último, cabe mencionar algunos aspectos en relación con la mediatización de la pandemia. El proceso de confinamiento ha producido múltiples cambios en las prácticas sociales. 
En este punto cabe destacar que se generó un doble movimiento. Por un lado, un proceso de pasaje a intercambios mediatizados (Fernández, 1994), de aquellos que se realizaban cara a cara (clases o encuentros entre amigos). Por otro lado, una acentuación de la mediatización (Verón, 2013) dado que intercambios que se desarrollaban cara a cara; pero que estaban atravesados con posterioridad por algún proceso de mediatización (como las sesiones del congreso), pasaron a desarrollarse plenamente bajo las formas de las prácticas digitalizadas (videollamadas por Zoom, WhatsApp, Jitsy, Skype, entre otros). En los programas periodísticos, el uso de los movileros y cronistas se vio, en muchos casos, reemplazado por la intervención de periodistas e invitados bajo el formato de la videoconferencia.

Este marco de pandemia mediatizada, que implica - como hemos especificado- una digitalización de las prácticas políticas, así como un cambio de las ya mediatizadas con anterioridad a la pandemia, podría ser conceptualizado como de transformación dentro del proceso histórico de mediatización de la política dado que se modificaron las relaciones de los internautas con las redes $-\mathrm{y}$ también de la relación de pares - ; así como el tipo de consumo de los medios tradicionales.

\subsection{Consumo mediático durante la pandemia mediatizada}

No es un dato menor mencionar que en estos meses de aislamiento obligatorio en Argentina, el consumo mediático se ha transformado. En «Entre recomendaciones y rutinas: Jóvenes \#en casa durante la cuarentena» - un relevamiento de jóvenes de 14 a 21 años, residentes en el Área Metropolitana de Buenos Aires Argentina, realizado entre abril y mayo de 2020-, se ha concluido que entre las actividades a las que los jóvenes dedican más tiempo durante el aislamiento social se encuentra en primer lugar: el «uso de redes sociales» (Tapia, 2020).

Por su parte, según la encuesta «Tecnología, noticias y entretenimiento en tiempos de aislamiento por el Covid-19» (Calzado, Lio y Cirulli, 2020), en la Ciudad Autónoma de Buenos Aires y Gran Buenos Aires el principal medio de información es Twitter (32\%); no obstante, en la población mayor de 45 años, «la televisión noticiosa» es muy importante (26\%), y el uso de WhatsApp entre la ciudadanía está centralmente dedicado al envío de memes y chistes $(46,4 \%)$. Estos datos ilustran, en parte, el proceso de postbroadcasting (Fernández, 2018), en el cual «el broadcasting no termina de irse (...) y las plataformas no terminan, o no pueden, ocupar ese espacio constructor de aldea global, ni siquiera a nivel país» (p. 26).

En este sentido Contursi y Tufró (2019) observan las interacciones entre el programa televisivo Intratables - que ocupa el prime time televisivo semanal- y Twitter, concluyendo que existen cuatro formas en las que aparece la red social: la mención al hashtag, la aparición de capturas de Twitter como archivo, el armado de una "escenografía» similar a la interfaz de Twitter y la utilización de la red social para darle lugar a la voz de la «gente» en pantalla.

\section{Metodología}

El objetivo del artículo es doble. Partimos de entender que la conferencia de prensa, en tanto acontecimiento político-mediático, genera una gran expectación; y por el otro, analizar las repercusiones que genera la conferencia de prensa en los internautas comunes y también 
en las propias redes sociales presidenciales. Así aspiramos a reconstruir el proceso de producción de sentido del entramado discursivo que contiene el acontecimiento políticomediático y los mensajes en las redes sociales vinculados con la conferencia de prensa, en el marco de la pandemia por Covid-19.

En lo que respecta a las repercusiones en Twitter indagamos en dos momentos específicos: por un lado, en las publicaciones que se sucedieron durante la conferencia de prensa presidencial que remitieron temáticamente al acontecimiento, tanto las producidas por el propio presidente en su Twitter como las de los internautas. Por otra parte, nos concentraremos en analizar el momento posterior a la conferencia: nos enfocaremos en los tweets producidos mientras se emitía el programa Intratables que tuvieran, sea como hashtag o como parte de su texto, una referencia al programa o a alguno de sus invitados. La elección de rastrear las repercusiones de la conferencia de prensa que temáticamente refieran a la emisión que contiene panelismo (Heram, 2018; Fernández, 2020) remite a capturar las interacciones que se generan en Twitter en un programa que dedica parte de su programación a discutir sobre la pandemia y que se transmitió en directo apenas terminó la conferencia de prensa de Alberto Fernández.

Teniendo en cuenta que el objeto que relevamos está enmarcado en medios masivos, plataformas y redes sociales, realizamos un análisis que contemple este marco específicamente mediático. Utilizamos herramientas que provienen de la sociosemiótica y de las conceptualizaciones sobre las redes sociales (Carlón, 2004; 2015; Fernández, 1994; 2018, 2020; Verón, 1987a; 2001 [1984]; 2013; Steimberg, 1993).

En relación con Twitter, apuntamos a capturar las variantes e invariantes de las repercusiones en las redes sociales de la transmisión en directo de la conferencia de prensa presidencial y de la posterior transmisión en directo de Intratables. De esta manera se podrá reconstruir el proceso de producción de sentido del entramado discursivo conferencia de prensa, Intratables y reacciones en Twitter. Para el análisis de los discursos generados en las redes sociales retomamos una clasificación de internautas que los diferencia teniendo en cuenta la triple destinación del discurso político (Verón, 1987b), el tipo de argumentación y el tipo de internauta político (Slimovich, 2012; 2016).

Retomamos en este trabajo la noción de «internautas ciudadanos», para referirnos a aquellos que postean sobre el tema en cuestión en las redes sociales pero que no están necesariamente anclados en su decir digital a una opción partidaria (Slimovich, 2012: 152). También aludiremos a los «internautas seguidores» (p. 149) de un político o partido, en correlación con la figura de pro-destinatario veroniano. Emergen bajo distintas formas y una de ellas es los «seguidores argumentadores lógicos» o internautas «seguidores pasionales» (p. 149); también existen los internautas «militantes fans» (p. 152); y en el otro polo, hay adherentes que se acercan a la «militancia descontracturada» (p. 145), entre otros modos de puesta en escena de la adherencia política en redes sociales. Por otro lado, nos referiremos a los «internautas opositores» (p. 152) en correlación con la figura de contra-destinatario veroniana, con sus distintas manifestaciones según la relación con lo político y si argumentan desde la vía de lo lógico o lo pasional (Barthes, 1985).

En consecuencia y por todo lo mencionado, el estudio aquí propuesto implica tener en cuenta la imbricación de distintos géneros, dispositivos, internautas, plataformas y medios. Por un lado, el estudio de los efectos de un acontecimiento político-mediático - la conferencia de prensa presidencial -, transmitido bajo el dispositivo del directo televisivo. A diferencia 
de lo que podría implicar el estudio de este objeto en la sociedad mediatizada, como hemos especificado, el analizar las repercusiones de la conferencia de prensa en la sociedad actual implica el estudio de las lógicas de lo masivo y las lógicas de las redes sociales, así como sus mixturas. De este modo, se ponen en juego los discursos de los internautas producidos en simultaneidad a la emisión en directo de la conferencia de prensa, así como de la emisión posterior de Intratables. Estos discursos suponen y reponen interfaces político-informativas (Verón, 2001 [1984]; Slimovich, 2016).

El corpus de análisis está conformado, por un lado, por los tweets emitidos desde la cuenta del presidente durante la conferencia y los que se produjeron con posterioridad pero que remitían temáticamente a la conferencia que él mismo había dado. Por otro lado, también analizaremos los mensajes que circularon en Twitter temáticamente en relación con la conferencia de prensa durante el tiempo que duró la misma y que se utilizaron alguno de los «trending topics» de ese momento; y, por último, tendremos en cuenta los mensajes en Twitter que se desarrollaron con posterioridad a la conferencia, durante la hora que duró temáticamente Intratables y que poseían como motivo temático a la emisión televisiva: algunos de sus temas o entrevistados.

Retomaremos así la distinción entre «motivo temático» y «tema» que plantea Segre (1985), teniendo en cuenta que los motivos son unidades mínimas de sentido, encapsulamientos que atraviesan los distintos textos, que se presentan en mayor cantidad que los temas y que en su articulación construyen el tema de un texto.

\section{La comunicación política de Alberto Fernández}

En el primer trimestre de su gobierno - de diciembre de 2019 a febrero de 2020 - se registraron en la cuenta de Twitter presidencial la difusión de «acontecimientos político-mediáticos», como el encuentro de Alberto Fernández con el Papa Francisco y el que tuvo con Emmanuel Macron, entre otros. En marzo, con la instauración del aislamiento preventivo y obligatorio en la Argentina por la pandemia por Covid-19 se evidencia una continuidad de la difusión de acontecimientos político-mediáticos en su Twitter, pero en este segundo trimestre de 2020 son mensajes que refieren a sus propias conferencias de prensa televisivas, cuyo tema es la pandemia.

Otro rasgo a destacar de la comunicación política de Alberto Fernández durante la pandemia es su aparición bajo diversos géneros, tipos de emisiones televisivas y grupos mediáticos. Fernández (2020) alude a la existencia de un «presidente en postbroadcasting»:

la palabra presidencial transmedia es, en general, sencilla, la que parece obtener consenso. Sin embargo, también en cada aparición, y reconocido aun entre sus seguidores, se anotan errores que se comentan también en todos los sistemas de intercambio (Fernández, 2020: 16).

En relación con su Twitter observamos la existencia de distintos tipos de interfaces político/periodísticas (Verón, 2001 [1984]; Slimovich, 2016) en el momento previo a la pandemia y que continúan durante. Nos referimos a operaciones en las que se replican contenidos de los medios periodísticos - tanto de los que poseen enunciación opositora como los que son afines - así como la «emulación de sus lógicas y géneros» (Slimovich, 2016). 


\section{Aberts Ferninder at retweet?}

Televisión Pùblica $\square$ aTV_Publica $-10 \mathrm{~h}$

'Por ahora el comienzo de clases no lo estamos vislumbrando' responde Q Gallertez. El Presidente de la Nación reafirma que el cierre de instituciones educativas, la suspensión de espectáculos públicos y el especial aisiamiento de los aduitos mayores continuian sin cambios.

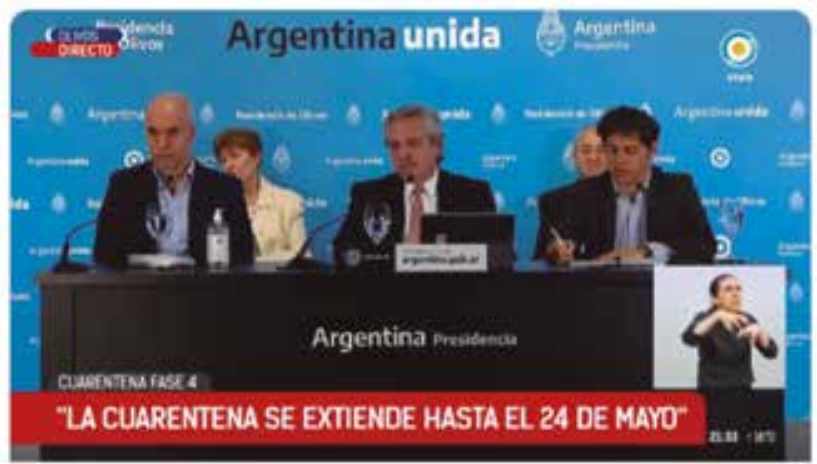

Conferencia de prensa de Alberto Fernandez

Figura 1. Fuente: Cuenta de Twitter de @alferdez: Alberto Fernández.

En efecto, durante las conferencias de prensa presidenciales emitidas desde marzo con la instalación del aislamiento obligatorio y preventivo en la Argentina se registran en la cuenta de Twitter presidencial interfaces político-periodísticas que replican contenidos de medios y de periodistas que contienen motivos temáticos ligados a la conferencia. En el caso que analizamos en este trabajo, en los discursos emitidos durante la conferencia presidencial del 8 de mayo y con posterioridad a la misma, se observa la existencia de retweets de la TV Publica que se integran a la propia enunciación política del presidente. Se trata de tweets que emitió la televisión estatal y que citan las propias palabras del presidente informando de que la cuarentena se extendía 15 días más y que los establecimientos educativos y las grandes reuniones de los espectáculos continúan cerrados (Fig. 1).

También se registran mensajes presidenciales que retweetean a personas públicas, médicos, economistas e incluso políticos opositores, como es el caso del retweet al jefe de Gobierno de la ciudad de Buenos Aires, con quien compartió la conferencia de prensa, junto con Axel Kicillof, el gobernador de la provincia de Buenos Aires y médicos/as prestigiosos del país.

Por otro lado, durante la conferencia de prensa el presidente se refirió a los políticos opositores a su gobierno que están en contra de la instalación del confinamiento en la Argentina y expresó: «hay opositores que gobiernan y lo hacen con la seriedad (...) y hay opositores que no gobiernan y en Twitter solo convocan con gran imprudencia al descuido de la gente». Estos momentos más polémicos de su discurso aparecen en su cuenta de Twitter, pero emergen en los retweets. Es decir, se trata de retweets que realiza el presidente de la cuenta de un político de la propia fuerza que cita sus propias palabras o que las reparafrasea. De este modo, la confrontación aparece mitigada. Es el caso del retweet de la cuenta de Wado de Pedro (Fig. 2). 


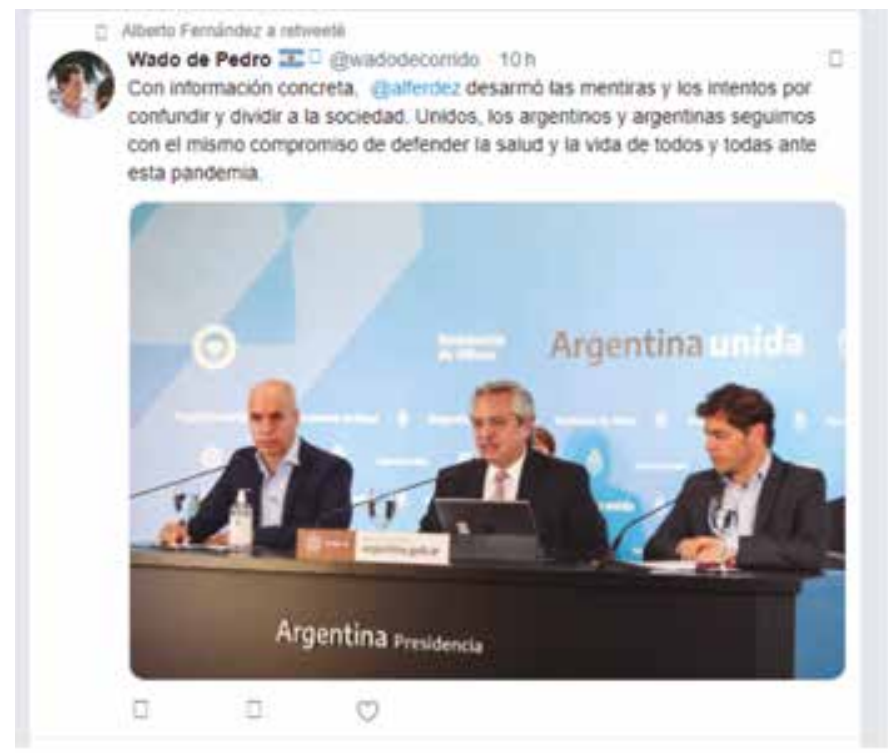

Figura 2. Fuente: Cuenta de Twitter de @alferdez: Alberto Fernández.

En conclusión, la cuenta de Twitter presidencial durante la pandemia se compone de diversas voces de gobernantes, funcionarios, políticos, periodistas, personas de los medios, y construye de este modo una enunciación coral político-mediática ${ }^{2}$.

En la sección siguiente, detallaremos cómo son los discursos de los internautas, tanto en el momento de la conferencia de prensa, como durante la emisión de Intratables, así como indagaremos en la conformación de esos colectivos político-mediáticos en las redes sociales

\section{Repercusiones en Twitter}

En cuanto a las repercusiones de los internautas en Twitter indagamos en dos momentos específicos: por un lado, en las publicaciones que se sucedieron durante la conferencia de prensa y que tuvieran entre sus motivos temáticos al acontecimiento político-mediático; y por el otro, en los tweets producidos mientras se emitía Intratables que tuvieran un hashtag, o como parte de su texto una referencia al programa o a alguno de sus invitados o entrevistados. En líneas generales podemos afirmar que en las repercusiones en las redes sociales se observa heterogeneidad temática y también distintos tipos de vinculación política con los entrevistados al programa y con el presidente.

En lo que respecta al momento de la conferencia las tendencias en Twitter muestran la conformación de dos colectivos anclados a diferentes hashtags. Por un lado. los adherentes al presidente se nuclean bajo el hashtag \#Alberto, \#Alberta y \#Albertotecuida. Este colectivo de internautas

2/ En relación con la enunciación, seguimos a Steimberg (1993) que postula que se trata de un «efecto de sentido de los procesos de semiotización por los que en un texto se construye una situación comunicacional, a través de dispositivos que podrán ser o no de carácter lingüístico» (p. 44). 


\section{\#AlbertoTeCuida}
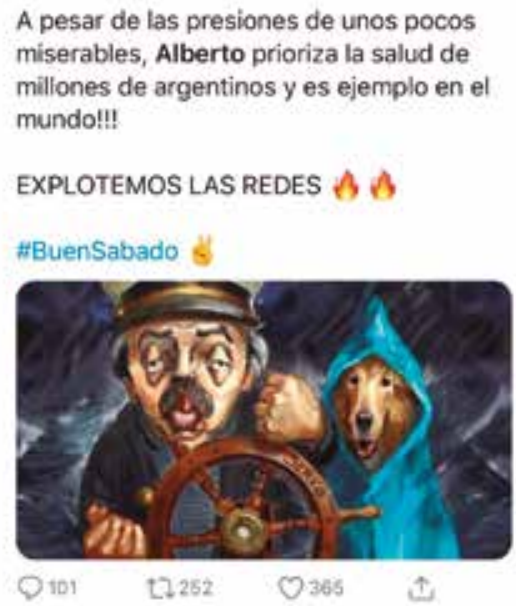

Figura 3. Fuente: cuenta de Twitter de @Cristian_2_27.

seguidores del presidente, se posicionan a la vez replicando «micro-argumentos lógicos» (Slimovich, 2012: 152) que justifican el confinamiento en los distintos sectores del país; y en ese punto, dado que son seguidores del presidente y que generan discursos políticos militantes a favor de la cuarentena, se posiciona como «internautas militantes de la cuarentena» (Figs. 3 y 4).

Por otro lado, el otro colectivo se posiciona como «opositor a la cuarentena» y se agrupa bajo el hashtag \#ConmiLibertadNo. En este punto se observa que el marco de la pandemia, y la cuarentena impuesta por el gobierno nacional, genera agrupamiento y enfrentamientos discursivos en las redes sociales que no se corresponden punto a punto con los destinatarios políticos clásicos: seguidores, opositores e indecisos a un partido o líder (Verón, 1987b), ni con los colectivos partidarios, sino en relación con la cuarentena y el aislamiento obligatorio que ella implica.

Las repercusiones en Twitter en el momento del acontecimiento político-mediático se orientan a tres temas (Segre, 1985) que se retoman del discurso del presidente transmitido por la televisión y replicado en streaming por sus redes sociales: 1) las fases de la cuarentena, 2) el cuestionamiento a la cuarentena y 3) la comparación Suecia/Noruega. En lo que respecta al primer punto, predominan en los mensajes en Twitter los motivos temáticos vinculados a la división del país en la región metropolitana de la ciudad de Buenos Aires y parte de la provincia (AMBA) y el resto del territorio de la nación. Se generan tweets que hacen alusión a la situación del AMBA, que es la única región que permanece en fase 3 y no

Figura 4. Fuente: cuenta de Twitter de @ MuchachoCuervo.

A muerte con vos Alberto. Siempre en contra de trolls y operetas que quieren solo que la gente se infecte y muera sin escrúpulos. \#QuedateEnCasa \#cuarentena \#albertotecuida 


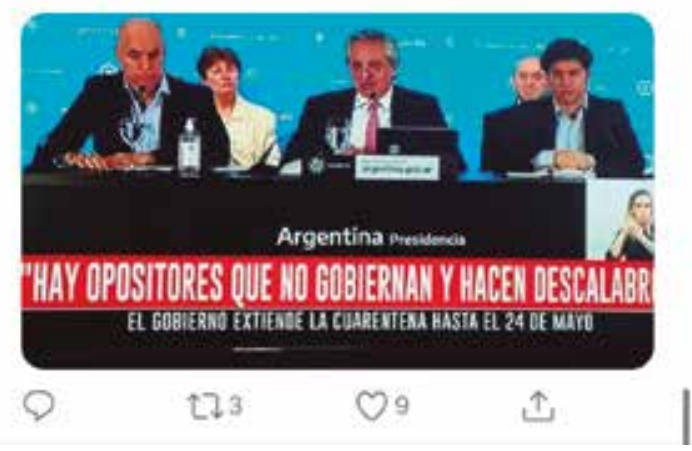

Figura 5. Fuente: cuenta de Twitter de @ rinconet.

avanza a fase 4. Este tipo de mensajes no genera el agrupamiento de colectivos políticos, ni se aglutinan en base a un hashtag.

En cuanto al segundo punto, se retoma el momento del discurso del presidente en que interpela a los opositores que critican la cuarentena y sí genera aglutinamientos que implican distintos tipos de vinculación con los destinatarios políticos. Así, se generan publicaciones en las cuales se da una interfaz político-informativa puesto que se comparten citas textuales de la conferencia y también capturas de pantalla televisivas. El modo de emergencia es a través de la aparición de operaciones de apropiación del contenido televisivo (Carlón, 2014). En efecto, los internautas citan la frase del presidente en la cual pide que los opositores «no le mientan más a la gente»; $y$ también el momento en el cual diferencia entre los que gobiernan y «los opositores que escriben en Twitter». En este punto cabe observar que se replican en la red social fragmentos de la conferencia de prensa en los cuales el presidente interpela explícitamente a los contra-destinatarios (Verón, 1987b), en un rasgo que fue característico del discurso kirchnerista desde la primera década del siglo xxı y que consiste en la interpelación a un «contradestinatario directo» (Montero, 2009): «una interpelación directa y en segunda persona (en ocasiones, en forma voseante), la contradestinación directa da lugar a un tono discursivo típicamente informal, juvenil y desafiante» (Montero, 2009: 321)3 (Fig. 5).

Creemos que este tipo de colectivo se conforma de modo análogo a los «militantes fans» (Slimovich, 2012: 152) que hemos mencionado con anterioridad: los que replican contenido político en sus propias cuentas en las redes sociales, usan hashtags políticos, cambian su foto de perfil para demostrar la adscripción político-partidaria. En este caso observamos la existencia de un colectivo de «fans»: mientras se desarrolla la conferencia estos internautas manifiestan en Twitter su adhesión al espacio político de Alberto Fernández utilizando hashtags que son «trending topic». A la vez, en los mensajes que emiten durante la conferencia construyen un

3/ Se registran múltiples casos de pantallas televisivas en relación con discursos de telespectadores. En relación con mensajes en pantalla que provienen de usuarios desconocidos mientras se desarrolla el directo televisivo confrontar con Carlón (2012). Otro caso es el del vivo de Instagram que replica la pantalla televisiva, en el cual se suceden los mensajes de internautas desconocidos y el internauta visualizador puede elegir ver los mensajes que provienen de otros internautas o no visualizarlos (Slimovich, 2018). Un antecedente mucho más antiguo de este tipo de mensajes proveniente de telespectadores en relación con lo televisivo, lo hallamos en los programas de entretenimiento nocturnos argentinos que poseían «foros» en la parte inferior de la pantalla con los mensajes de los interlocutores telefónicos (Slimovich, 2007). 


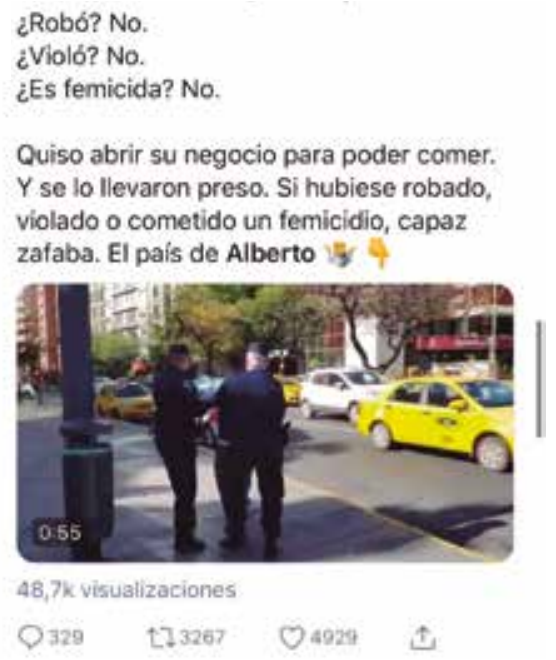

Figura 6. Fuente: cuenta de Twitter de @chauoperetak.

adversario político que tiene un carácter distintivo dado que no es necesariamente el que está en un partido político diferente al del presidente, -aunque corresponda a ese segmento político-; sino que se interpela a los internautas que están en contra de la cuarentena para poder abrir la «economía del país». Asimismo, y en correlación con su posición de «seguidores» del presidente se posicionan como «internautas militantes de la cuarentena».

En definitiva, este colectivo se configura como seguidor del presidente y asimismo posicionan como su «contradestinatario» a los opositores a la cuarentena, al realizar esta interpelación lo hacen en correlación con el argumento del presidente que expresa: «hay opositores que gobiernan y lo hacen con la seriedad y hay opositores que no gobiernan y en Twitter solo convocan con gran imprudencia al descuido de la gente».

Por otra parte, también se observa la conformación de un colectivo de internautas que son opositores a la cuarentena, y justamente utilizan argumentos a favor de «la necesidad de parar la caída del empleo», "la necesidad de que la gente consuma», entre otros. Es decir, los mensajes de los opositores a la cuarentena replican los mismos motivos temáticos que los internautas seguidores del presidente, pero se posicionan claramente a favor de priorizar la economía. Este colectivo tiende a producir «micro-argumentaciones pasionales» (Slimovich, 2012: 152). Nos referimos a argumentaciones breves condensadas de sentido que generan operaciones figurales en relación a la continuidad de la cuarentena en el país, como las hipérboles o sinécdoques, para generar emociones en los internautas (Fig. 6).

En lo que respecta al tercer punto, la comparación que realiza el presidente con Noruega y Suecia, cabe mencionar que generó múltiples reacciones en las redes sociales. Por un lado, desde una mirada económica, los que sostienen que no es conmensurable esas sociedades con la Argentina y utilizan expresiones hiperbólicas e ironías, además de cifras que no son oficiales y cuya fuente no aparece explícita (Figs. 7 y 8 ). Por otro lado, los que creen que es una muestra de que se está trabajando bien en el país por la cuarentena, puesto que podemos compararnos con países nórdicos (Fig. 9). Esta comparación con los países europeos 
"Si abrimos la economía vamos a terminar
como termino Suecia" Ojalá el universo te
escuché Alberto \#ViernesDeRiesgo
\#cuarentena \#8Mayo \#ConMiLibertadNo

Figura 7. Fuente: cuenta de Twitter de @yasiboop.

Alberto, no hables de Suecia, ni de Noruega, tampoco de Estados Unidos. Habla un poco de las 500mil Pymes que se están fundiendo y de los millones que no pueden laburar hace más de $\mathbf{4 0}$ dias.

Figura 8. Fuente: cuenta de Twitter de @ulichaparro12.

no está necesariamente vinculada a destinatarios políticos, en el caso de los internautas de Twitter. Es decir, son tanto los internautas seguidores del presidente, como los opositores a la cuarentena, los que tweetean sobre esta cuestión.

En relación con los tweets producidos mientras se emitía Intratables que tuvieron como hashtag, o como parte de su texto, una referencia al programa o a alguno de sus invitados o entrevistados, cabe una primera mención en torno a la existencia de internautas que no están nucleados ni agrupados bajo un hashtag; no obstante, tweetean sobre el programa y sobre el discurso del presidente, del jefe de gobierno o del gobernador de la provincia de Buenos Aires. Cabe mencionar que Intratables no usó hashtag en la pantalla televisiva como lo hace habitualmente, generando una dispersión de los internautas.

Como hemos mencionado anteriormente, en la conferencia de prensa, uno de los motivos temáticos recurrentes fue el de la necesidad de «extender» la cuarentena en toda la Argentina. Es decir, prolongar en la región metropolitana del AMBA el aislamiento social y obligatorio tal como estaba instalado antes de que el presidente de la nación, el jefe de gobierno de la ciudad de Buenos Aires y el gobernador de la provincia de Buenos Aires hablaran en la conferencia de prensa. Asimismo, se anuncia el pasaje de fase 3 a fase 4 del resto del país. En el relevamiento realizado en Twitter, cabe observar la existencia de diferentes colectivos y diferentes motivos temáticos vinculados a la decisión del presidente de prolongar el aislamiento.

Por un lado, la existencia de un colectivo de «internautas opositores» a la cuarentena que a la vez se posicionan como «opositores» al presidente. En este punto se observa una alineación entre el tipo de internauta y el tipo de destinatario político que también observamos en el

\section{¿les gusta comparar con otros paises? \\ Alberto hizo la comparación con números y datos de consecuencias de la cuarentena asi dejen de especular y darse de conocedores}

Figura 9. Fuente: cuenta de Twitter de @david_j. 


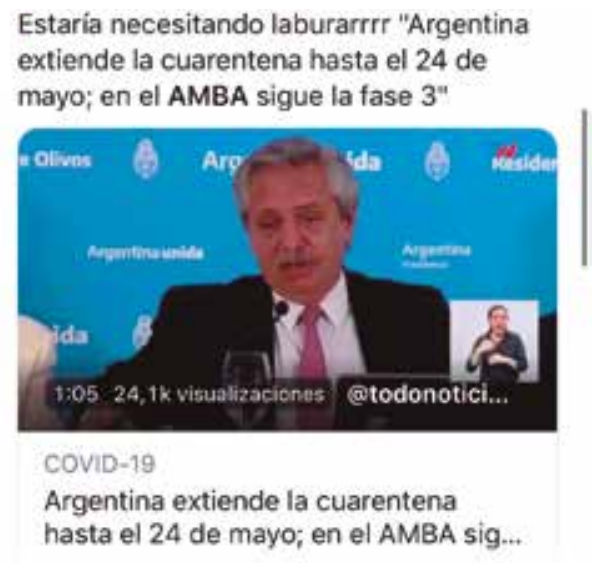

Figura 10. Fuente: cuenta de Twitter de @caaaaaami.

momento de la conferencia de prensa. Es decir, durante la conferencia de prensa y durante la emisión de Intratables, en Twitter se registran mensajes que aluden a la necesidad de terminar con el aislamiento y se posicionan políticamente como opositores al Frente de Todos. No obstante, una de las diferencias entre el momento de la transmisión de la conferencia de prensa y el momento posterior, en cuanto a repercusiones en Twitter, es que mientras se desarrolla Intratables predomina entre los mensajes del colectivo opositor a la cuarentena el motivo temático de «abrir la economía», en simultaneidad con el argumento esgrimido por el diputado Carrino en Intratables quien plantea la necesidad de «flexibilizar la cuarentena». Se evidencia en la emisión televisiva una predominancia de los motivos temáticos que están en relación con la necesidad de generar apertura de comercios e industrias. Este tipo de argumentos es el que aparece más replicado en el colectivo de opositores.

Por otro lado, se replica el motivo temático que aparece mencionado por el conductor de Intratables vinculado a la necesidad de trabajar que tienen sectores de la población (Fig. 10). Dentro de los mensajes producidos en Twitter por este colectivo opositor a la cuarentena, se observa la reposición de contenidos de medios de comunicación opositores al kirchnerismo y peronismo, como $T N$.

Asimismo, uno de los motivos temáticos que aparece entre los mensajes que se desarrollan en Twitter, es el hecho de que, en la Ciudad Autónoma de Buenos Aires, el Jefe de Gobierno, Horacio Rodríguez Larreta, decidió volver a implementar, en el contexto de cuarentena, la penalización por mal estacionamiento de la grúa. En este punto se observa que surgen motivos temáticos que no están directamente vinculados a la conferencia de prensa (el disparador es simplemente la existencia en pantalla - y en la conferencia presidencial- del jefe de gobierno) y que no aparecen mencionados en la emisión televisiva de Intratables que se desarrolló en directo con posterioridad a la emisión y cuya temática versó en la conferencia de prensa presidencial.

Por otro lado, hay un momento de la emisión de Intratables que genera muchas repercusiones en las redes sociales y es la entrevista a Carlos Ruckauf. Se trata de la última entrevista del programa, por consiguiente, es la más alejada de la conferencia de prensa, 


\section{Ustedes no hablan nacido, pero hace más o menos una hora Doman dijo que está en contra de darle aire a funcionarios que fracasaron (ejemplo: Prat Gay). Ahora, y sin ponerse colorado, está entrevistando a Carlos Ruckauf, que le tiró la Provincia -incendiada- por la cabeza a Solá.}

Figura 11. Fuente: cuenta de Twitter de @cagnacci_

y la que menos tiempo de emisión tuvo. No obstante, es la que mayor cantidad de mensajes genera en Twitter. Es decir, es la elección por parte de la producción del programa, del entrevistado y de pedirle una opinión económica, lo que genera las reacciones de los internautas, más que las opiniones y el debate sobre la conferencia de prensa. En este punto, la tensión entre la gramática de recepción (Verón, 1987a) vinculada a la política se impone por sobre lo que sucede en la pantalla, en la cual Ruckauf se centra en explicar la situación económica que él debió manejar en 2001, y las diferencias con el momento actual. No obstante, en Twitter se impone la pregunta por la pertinencia de entrevistar a Ruckauf por parte de la producción del programa, dado que se le critica invitar a hablar como «voz autorizada» a un político que no pudo en su momento gestionar de manera eficiente la crisis económica, social y política en la provincia de Buenos Aires (Fig. 11). Se configura en Twitter un colectivo de «internautas seguidores» del Frente de Todos, que apelan a «micro-argumentaciones lógicas» (Slimovich, 2012: 152) en contra de la aparición de Ruckauf en el programa como «Voz autorizada».

\section{Conclusiones/Discusión}

Luego de realizado el análisis de las discursividades del presidente en Twitter y los mensajes de los internautas en reacción con la conferencia de prensa, una primera conclusión es que la tensión economía/salud que atraviesa la conferencia de prensa del presidente - y la agenda mediática desde el inicio de la cuarentena- está presente también en las repercusiones en las redes sociales de la conferencia de prensa.

Asimismo, se observa una tendencia a la polarización de las posiciones durante la conferencia de prensa presidencial. Por un lado, se genera el aglutinamiento de internautas defensores de la cuarentena que se posicionan como adherentes al gobierno nacional. Por otro lado, un colectivo de opositores a la cuarentena, que manifiestan su rechazo a la decisión gubernamental de extender la cuarentena y enunciativamente tweetean desde la preocupación por la economía del país. No se trata de un colectivo que sea adherente a una fuerza o partido, sino que se nuclea desde la negatividad a la continuidad de la cuarentena.

Por otro lado, cabe resaltar que en el estudio de las discursividades presentes en Twitter y que utilizaban alguno de los hashtags que fue «trending topic» durante la conferencia de prensa no se registra «internautas ciudadanos» puesto que los internautas manifiestan adherencia al Frente de Todos y al presidente, o bien su rechazo. No obstante, no se registran mensajes que utilicen los hashtags y que se configuren como indecisos virtuales. 
Por último, se observa una diferencia en el tipo de discursividad puesta en juego por los tipos de internautas. Los seguidores del presidente tienden a construir «micro-argumentaciones lógicas» y operaciones de interfaz con los medios periodísticos, en paralelo a lo que observamos que se realiza desde la cuenta de Twitter del presidente. Por el contrario, los opositores a la cuarentena tienden a construir «micro-argumentaciones pasionales» que apuntan a producir emociones negativas en otros internautas, como el miedo o la bronca a través de comparaciones, exageraciones y contigüidades, utilizando en algunos casos, cifras $y$ datos que no poseen fuente.

\section{Bibliografía}

ANNUNZIATA, Rocío, ARIZA, Andrea Fernanda y MARCH, Valeria Romina (2018). «"Gobernar es estar cerca". Las estrategias de proximidad en el uso de las redes sociales de Mauricio Macri y María Eugenia Vidal». Revista Mexicana de Opinión Pública, (24), 71-93. DOI: 10.22201/ fcpys.24484911e.2018.24.61520

BARTHES, Roland (1985). La aventura semiológica. Barcelona: Paidós.

CALZADO, Mercedes, LIO, Vanesa, CIRULLI, Ailén (2020). "¿Cómo nos informamos durante la cuarentena? Tecnologías, noticias y entretenimiento en tiempos de aislamiento por el Covid-19». Comunicación, Política y Seguridad Recuperado de http://www.comunicacionyseguridad.com/ analisis-medios/

CARLÓN, Mario (2015). «Público, privado e íntimo: el caso Chicas bondi y el conflicto entre derecho a la imagen y libertad de expresión en la circulación contemporánea». En Castro, P. César (Org.). Dicotomia público/privado: estamos no caminho certo? Maceió, Brasil: EDUFA, págs. 211-232.

CARLÓN, Mario (2014). «¿Del arte contemporáneo a una era contemporánea?». En Rovetto, Florencia, y Reviglio, María Cecilia (Eds.). Estado actual de las investigaciones sobre mediatizaciones. Rosario, Argentina: UNR Editora, pp. 24-41. Recuperado de http://www.cim.unr.edu.ar/archivos/ cuadernodelcim2.pdf

CARLÓN, Mario (2012). «En el ojo de la convergencia. Los discursos de los usuarios de Facebook durante la transmisión televisiva de la votación de la ley de matrimonio igualitario». En Carlón, Mario y Neto, Antonio Fausto (Comps.). Las políticas de los internautas. Nuevas formas de participación. Buenos Aires: La Crujía, págs. 173-194.

CARLÓN, Mario (2004). Sobre lo televisivo. Dispositivos, discursos y sujetos. Buenos Aires, Argentina: La Crujía.

CONTURSI, María Eugenia y TUFRÓ, Manuel (2019). «La grieta garpa. Intratables y la reinscripción del antagonismo político en el infoentretenimiento». En REDCOM 2019, Salta, Argentina. Recuperado de https://www.aacademica.org/maria.eugenia.contursi/4

COULDRY, Nick (2014). «Mediatization and the future of field theory». In Lundby, K. (Ed.), Mediatization of communication. Berlin, Alemania: De Gruyter Mouton, págs. 227-248.

DAYAN, Daniel y KATZ, Elihu (1992). La historia en directo. La retransmisión televisiva de los acontecimientos. Barcelona, España: Editorial Gustavo Gili.

FERNÁNDEZ, José Luis (1994). Los lenguajes de la radio. Buenos Aires, Argentina: Atuel.

FERNÁNDEZ, José Luis (2018). “Comprender las plataformas mediáticas». En Fernández, José Luis. Plataformas mediáticas. Elementos de análisis y diseño de nuevas experiencias. Buenos Aires, Argentina, Argentina: La Crujía, págs. 29-62. 
FERNÁNDEZ, José Luis (2020). «Un presidente entre la pandemia y el postbroadcasting». Revista Question (1), 1-27. DOI: 10.24215/16696581e301

FERNÁNDEZ, Mariano Néstor y CINGOLANI, Gastón (2019). Cristina, un espectáculo político. Cuerpos, colectivos y relatos en la última presidencia televisiva. Buenos Aires, Argentina: Prometeo.

GINDIN, Irene (2019). «Ethos íntimo». En Gindin, Irene. Mi aparente fragilidad. La identidad política en el discurso de Cristina Fernández de Kirchner: 2007-2011. Buenos Aires, Argentina: Prometeo, pp. 97-106.

HERAM, Yamila (2018). «Intratables: el panelismo de "todas las voces todas"». Pilquen, 21(2). Recuperado de http://revele.uncoma.edu.ar/htdoc/revele/index.php/Sociales/article/view/1905/pdf

HJARVARD, Stih (2008). "The mediatization of society. A theory of the media as agents of social and cultural change». Nordicom Review, 29(2), 105-134. Recuperado de http://www.nordicom.gu.se/ sites/default/files/kapitel-pdf/269_hjarvard.pdf

HJARVARD, Stih (2014). A midiatizacao da cultura e da sociedad. San Leopoldo: Editora Unisinos.

MAZZOLENI, Gianpietro y SCHULZ, Winfried (1999). «Mediatization of politics: A challenge for democracy?». Political Communication, 16(3), 247-261.DOI: 10.1080/105846099198613

SEGRE, Cesare. (1985). «Tema / motivo». En Segre, Cesare. Principios de análisis del texto literario. Barcelona, España: Crítica.

SLIMOVICH, Ana (2007). Vos y voz en pantalla: el teléfono en el directo televisivo no ficcional. Tesis de Licenciatura en Ciencias de la Comunicación, Facultad de Ciencias Sociales de la Universidad de Buenos Aires. Buenos Aires.

SLIMOVICH, Ana (2012). «El Facebook de los gobernantes. El caso de Cristina Fernández de Kirchner y de Mauricio Macri». En Carlón, Mario y Neto, Antonio Fausto (Comps.). Las políticas de los internautas. Nuevas formas de participación. Buenos Aires: La Crujía, págs. pp. 137-154.

SLIMOVICH, Ana (2016). La interfaz entre lo político y lo informativo en la mediatización televisiva y las redes sociales en las campañas argentinas de 2009 y 2011. Tesis doctoral no publicada. Facultad de Ciencias Sociales de la Universidad de Buenos Aires, Buenos Aires.

SLIMOVICH, Ana (2017). «La ruta digital a la presidencia argentina. Un análisis político e hipermediático de los discursos de Mauricio Macri en las redes sociales». Dixit, 26, 24-43. DOI: 10.22235/d. v0i26.1321

SLIMOVICH, Ana (2018). «La política en Instagram. El metacuerpo presidencial: los internautas ciudadanos, seguidores y opositores». Bordes. Revista de Política, Derecho y Sociedad, 24 agosto. Recuperado de http://revistabordes.com.ar/la-politica-en-instagram/

SLIMOVICH, Ana (2019). «La mediatización contemporánea de la política en Instagram. Un análisis desde la circulación hipermediática de los discursos de los candidatos argentinos». Revista Sociedad, 39, (noviembre 2019 a abril 2020), 31-45. Recuperado de https://publicaciones.sociales. uba.ar/index.php/revistasociedad/article/view/5088/4222

SLIMOVICH, Ana (2020). "El camino de Cambiemos en las redes sociales: entre las lógicas políticas y las mediáticas». En Aymá, Ana y Dagatti, Mariano (Comps.). La política en escena: voces, cuerpos e imágenes en la Argentina del Siglo XXI. Quilmes, Argentina: Universidad Nacional de Quilmes, págs. 183-200.

STEIMBERG, Óscar (1993). Semiótica de los medios masivos. Buenos Aires, Argentina: Atuel. STRÖMBÄCK, Jesper (2008). «Four phases of mediatization: An analysis of the mediatization of politics». International Journal of Press/Politics, 13(3), 228-246. DOI: 10.1177/1940161208319097 
TAPIA, Silvia Alejandra (2020). Entre recomendaciones y rutinas: Jóvenes \#encasa durante la cuarentena (Buenos Aires, Argentina). Resultados de encuesta durante el aislamiento social, preventivo y obligatorio por COVID 19.

VERÓN, Eliseo (2013). La semiosis social, 2. Ideas, momentos, interpretantes. Buenos Aires, Argentina: Paidós.

VERÓN, Eliseo (2001 [1984]). El cuerpo de las imágenes. Buenos Aires, Argentina: Norma.

VERÓN, Eliseo (1998 [1995]). «Mediatización de lo político». En Gauthier, Gilles, Gosselin, André y Mouchon, Jean (Comps.). Comunicación y política. Barcelona, España: Gedisa, págs. 220-236.

VERÓN, Eliseo (1987a). La semiosis social. Barcelona, España: Gedisa.

VERÓN, Eliseo (1987b). «La palabra adversativa. Observaciones sobre la enunciación política. En Verón, Eliseo El discurso político. Lenguajes y acontecimientos. Buenos Aires, Argentina: Hachette.

VERÓN, Eliseo (1986). La mediatización. Buenos Aires, Argentina: Facultad de Filosofía y Letras. Universidad de Buenos Aires. 